(c) 2015, Elsevier. Licensed under the Creative Commons Attribution-NonCommercial-NoDerivatives 4.0 International http://creativecommons.org/licenses/by-nc-nd/4.0/

\title{
Estimation of Computer Waste Quantities Using Forecasting Techniques
}

Nikolaos Petridis ${ }^{\mathrm{a}}$, Emmanouil Stiakakis $^{\mathrm{b}}$, Konstantinos Petridis $^{\mathrm{c}}$, Prasanta Dey, $^{\mathrm{c}, *}$

aDepartment of Economics, Aristotle University of Thessaloniki, University Campus, 54124, Thessaloniki, Greece, e-mail: petridin@auth.gr

bDepartment of Applied Informatics, 156 Egnatia str., 54006, Thessaloniki, Greece, e-mail: stiakakis@uom.gr

'Operations and Information Management, Aston Business School, Aston University, Birmingham, UK, e-mail: \{k.petridis@ aston.ac.uk, p.k.dey@aston.ac.uk\}

* Corresponding author, Tel: +44 121204 4011, Fax:+44 121204 5271, e-mail: p.k.dey@aston.ac.uk 


\begin{abstract}
Technology changes rapidly over years providing continuously more options for computer alternatives and making life easier for economic, intra-relation or any other transactions. However, the introduction of new technology "pushes" old Information and Communication Technology (ICT) products to non-use. E-waste is defined as the quantities of ICT products which are not in use and is bivariate function of the sold quantities, and the probability that specific computers quantity will be regarded as obsolete. In this paper, an e-waste generation model is presented, which is applied to the following regions: Western and Eastern Europe, Asia/Pacific, Japan/Australia/New Zealand, North and South America. Furthermore, cumulative computer sales were retrieved for selected countries of the regions so as to compute obsolete computer quantities. In order to provide robust results for the forecasted quantities, a selection of forecasting models, namely (i) Bass, (ii) Gompertz, (iii) Logistic, (iv) Trend model, (v) Level model, (vi) AutoRegressive Moving Average (ARMA), and (vii) Exponential Smoothing were applied, depicting for each country that model which would provide better results in terms of minimum error indices (Mean Absolute Error and Mean Square Error) for the in-sample estimation. As new technology does not diffuse in all the regions of the world with the same speed due to different socio-economic factors, the lifespan distribution, which provides the probability of a certain quantity of computers to be considered as obsolete, is not adequately modeled in the literature. The time horizon for the forecasted quantities is 2014-2030, while the results show a very sharp increase in the USA and United Kingdom, due to the fact of decreasing computer lifespan and increasing sales.
\end{abstract}

Keywords: E-waste generation, Lifespan, Forecasting, Distribution Fitting 


\section{Introduction}

Electrical and electronic products that reach the end of their useful life become obsolete. This obsolete equipment is known as Waste Electrical and Electronic Equipment (WEEE) or electronic waste (e-waste) and nowadays constitutes one of the fastest growing waste streams. Advances in technologies, decreasing trends in prices, and changes in consumer habits have led to fast replacement of electronic products with new ones having shorter life cycles (Dwivedy and Mittal, 2010). As a consequence, a significant growth and accumulation of large e-waste quantities occurs. The "Solving the E-Waste Problem (StEP) Initiative", which is a multi-stakeholder network of governmental and scientific organizations, universities, and companies under the umbrella of United Nations, forecasts that by 2017 the world will produce 72 million tons of e-waste, increased by 33 percent compared to 2012 .

E-waste contains valuable and hazardous materials and if are not handled properly could lead to lack of resources and serious environmental and economic problems (Menikpura et al., 2014). Recognizing the importance of the e-waste stream and its impact, developed countries have established regulations and directives to manage the e-waste disposal and treatment (Wakolbinger et al., 2014), and enhance the economic, environmental, and social benefits of all the involved companies (Yeh and $\mathrm{Xu}, 2013$ ). In Europe, this has evolved in two directives: the Restriction of Hazardous Substances (RoHS) directive which limits the use of toxic and hazardous substances in the electronic equipment (European Commission-RoHS Directive, 2003) and the WEEE Directive (European Commission-WEEE Directive, 2003), which encourages reuse, recovery, and recycling of e-waste while at the same time imposes measures to reduce accumulation in landfills (Nelen et al., 2014). The WEEE Directive, established in 2003, dictated an average collection target of $4 \mathrm{~kg}$ per individual per year for every member state. However, a recast of the Directive in 2012 imposes $45 \%$ of EEE placed on the market as a minimum collection rate from the year 2016, while from the year 2019 this rate increases to $65 \%$ annually.

The continuously increasing generation of e-waste and their inappropriate disposal raise the scientific community's concern, as well as the interest of manufacturers, governments, managers, and citizens. Designing and developing an efficient management system of e-waste, along with suitable and effective collection and treatment of the respective products, are dependent on a great number of factors, such as the size of the country or city, the methods and means of collection, recycling behavior, handling and processing of end-of-life products (Johansson and Luttropp, 2009), technology innovation ( $\mathrm{Lu}$ et al., 2015), etc. For instance, the use of an integrated mobile recycling plant could solve e-waste problem for small countries or cities (Zeng et al., 2015). The extent to 
which formal or informal collectors participate in the overall collection system (Chi et al., 2014) and the lack of appropriate infrastructure in collection centers (Qu et al., 2013) are important factors as well. However, the estimation of e-waste generation constitutes the top priority issue and fundamental input for the design, operation, and optimization of e-waste management systems. A reliable estimate of e-waste generation is necessary to stakeholders and waste management service companies in order to develop efficient disposal, collection, and treatment strategy. Generally, the majority of households have knowledge about the impact of e-waste on environment and health (Afroz et al., 2013); however, until now there have not been sufficiently accurate figures for the amount of e-waste and certainly not a widely accepted methodology to estimate e-waste quantities. This constitutes a crucial need and it was the motivation for this paper. Taking into account that ewaste is a complex stream since it includes a wide range of products, the paper focuses on the case of Information and Communication Technologies (ICTs) and particularly their main product, i.e. personal computers (PCs). Lifespan can be defined in various ways depending on the estimation method and data that are available in each case (Murakami et al., 2010). The expansion of ICT products and the continuously decreasing lifespan of that category of products have made ICT waste a major contributor to the overall quantity of e-waste.

In this work, we propose an approach for the estimation of e-waste generation (obsolete computer quantities). A graphical illustration of the paper's proposed work is depicted in Figure 1. 


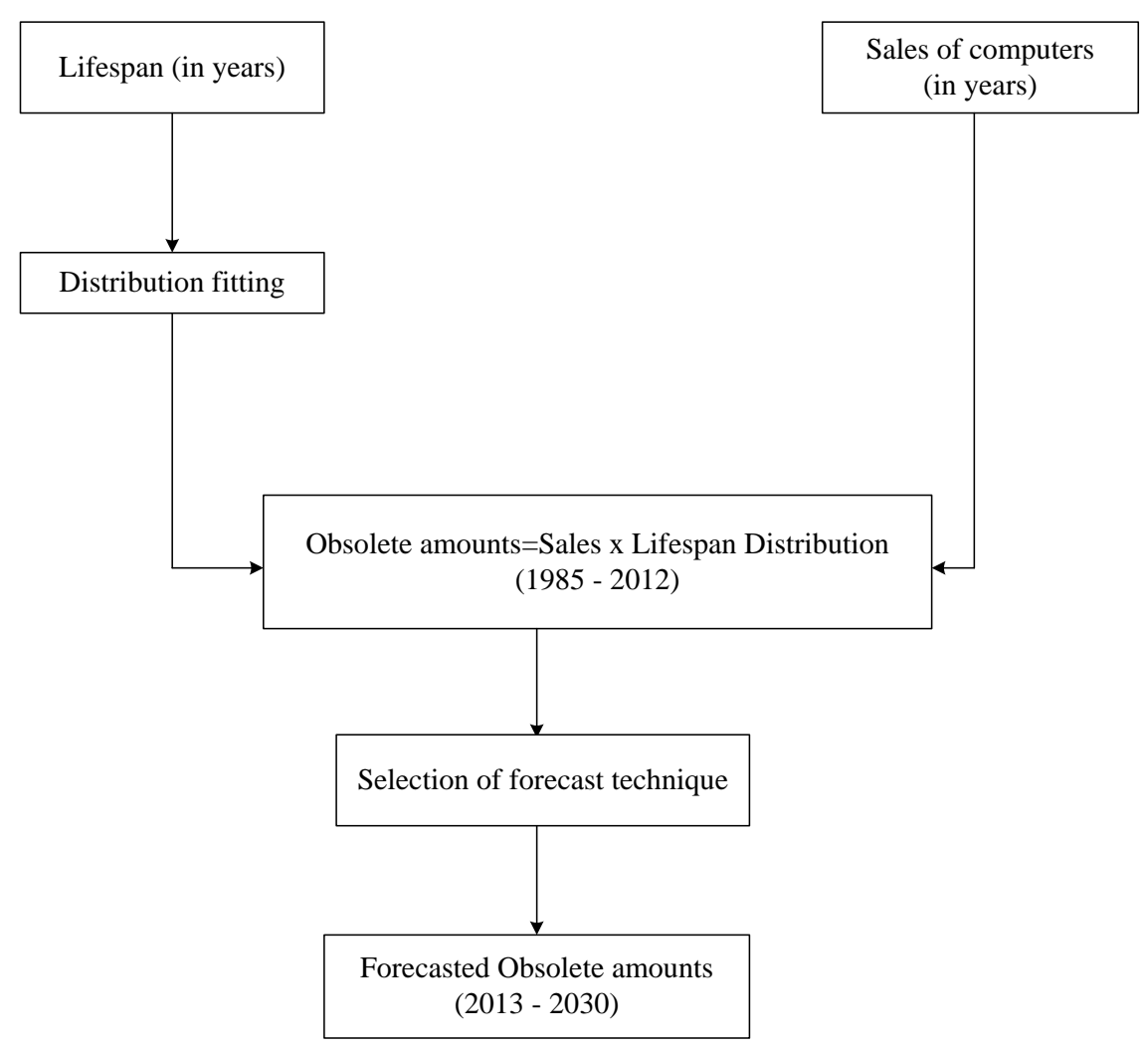

Figure 1: Graphical illustration of the proposed work

Due to each region's socio-economic environment, lifespan distribution varies as demonstrated in the work of Yu et al. (2010). Obsolete computer quantities are defined as an expected value of the sales of computers with the probability this quantity of computers to be considered as obsolete. Yet, as there is a different lifespan distribution in each of the regions of the world, each region is tested based on fitting indices with the widely known continuous distributions that have been utilized, up to now, to model this specific type of data (Normal, Weibull, Lognormal, Logistic, Cauchy, and Exponential) (Babbitt et al. 2009).

The obsolete computer quantities are estimated for the same time horizon as the historical computer sales data. From each region the biggest countries (in terms of economic development and welfare) are selected as surrogates. Several statistical methods are tested upon predicting validity indices in order to evaluate which is the best to be used for the out of sample forecast. Aim of this study is to provide a holistic estimation regarding the amounts of obsolete computers generated over the years, something that has not been proposed in the extant literature.

The rest of the paper is analyzed as follows: in Section 2, a detailed literature review reveals the literature gap. In Section 3, the mathematical model for the estimation of e-waste quantities is 
described, while the results are presented in Section 4. The results are discussed in Section 5 and finally, we conclude in Section 6.

\section{Literature Review}

There are various methods to estimate e-waste generation. One of the most common methods is the 'market supply', in which production and sales data are combined with lifespan to estimate e-waste quantities. According to this method, the total amount of electronic product sales in one particular year becomes waste when their average lifespan ends (Jain and Sareen, 2006). The application of the market supply method is highly dependent on the assessment of the lifespan of the electronic equipment. A variant of this method is the 'market supply A' method, which assumes that lifespan of electronic equipment follows a statistical distribution. Matthews et al. (1997), proposed a model to estimate the quantities of PC waste considering that after the end of lifetime there are four options: (i) reuse, (ii) storage, (iii) recycling, and (iv) landfill. They calculated the generation of obsolete PCs by combining sales data of ten years, average lifespan, and percentages of the end of life options. Another widely used method is the 'consumption and use', which estimates e-waste quantities based on the stock levels of electronic devices in households. Kumar and Shrihari (2007) forecasted the waste amount of five electronic appliances in India for the period 2006-2015, using the methods of market supply, market supply A, and consumption and use.

In the study of Araújo et al. (2012), e-waste generation in Brazil was calculated for the years 20002008 considering the distinction of e-waste in mature markets (e.g. refrigerators, washing machines, televisions) and non-mature markets (e.g. PCs, mobile phones). In order to estimate the quantity of ewaste of a mature market and taking into account that their sales are made to replace products at the end of their life, the consumption and use method was used. This method is based on the number of appliances owned by households (stock in use) divided by the average lifetime of the appliance. On the contrary, the time step method is considered more suitable for non-mature markets.

Robinson, in his study (2009), proposed an equation for the calculation of the contribution of an electronic product in the annual generation of e-waste, depending on the mass of the product, the number of units in use, and its average lifetime. Chung et al. (2011) applied this equation to estimate e-waste quantities in Hong-Kong, with the difference that instead of units in use, they used the amount of products stored and the amount of units owned by households. There are a number of studies that use Material Flow Analysis (MFA) to forecast e-waste quantities (Streicher-Porte et al., 2005; Steubing et al., 2010; Zhang et al., 2011; Yang and Williams, 2009; Dwivedy and Mittal, 2010). These studies are based on material balancing and the principle of mass conservation which basically denotes that all flows leaving a process are equal to all flows that have entered the same 
process. Streicher-Porte et al. (2005) indicated three types of MFA: (i) Substance Flow Analysis (SFA), (ii) Process-based MFA, and (iii) Industry-based MFA. They applied Process-based MFA focusing on the comprehension of the e-waste recycling system, its characteristics, and its performance. Their model was used to calculate waste quantities of PCs in New Delhi, India, for the period 1996-2003, assuming two scenarios for the average lifespan (5 and 7 years).

Steubing et al. (2010) assumed that recycling and disposal are the final processes at the end of life cycle of computers and proposed that the amount of e-waste can be calculated as the sum of the flows that enters these processes. They conducted a survey with questionnaires and interviews and considered three scenarios (baseline, upper, and lower) to estimate residence times in processes and transfer coefficients, which represent the percentage of flows from one process to others. Their model was applied in Chile in order to estimate computer waste for the period 1996-2020 using scenarios for residence times, transfer coefficients, and average lifespan of computers, as well as historical sales data and projections for future sales data by making assumptions about the market growth. Similarly, Zhang et al. (2011) developed a forecasting model based on electronic product inflows and outflows in a society, and on the change of stock in use. The model estimates the waste quantities of five household appliances (air conditioners, refrigerators, washing machines, color TV sets, and PCs) in Nanjing, China, using the year 2009 as initial value for the calculations and forecasting the flows until 2050 by extrapolating the number of households and the appliances per household.

In the study of Yang and Williams (2009), a logistic model was developed in order to estimate the amount of obsolete computers (desktops and laptops). The main concept herein is to calculate the penetration rate of computers, translate it to computer sales, which in combination with the average lifespan leads to the estimation of obsolete computers. Sales data from 1978 to 2008, sales projections, PC penetration rates in households and businesses, average lifespan of PCs, and bounding analysis, which formulates baseline, lower, and upper line scenarios for lifespan and penetration rate, are used in the proposed model to estimate the generation of obsolete computers until 2009. This logistic model was also used by Dwivedy and Mittal (2010) to forecast the amount of obsolete computers until 2026 in India. In this research, historical sales from 1994 to 2007 were used as initial input. Apart from the logistic model, Dwivedy and Mittal used MFA proposing two scenarios, one optimistic and one pessimistic, to make assumptions on the amount of computers that ends up in reuse, storage, recycling, and landfill. The logistic model and MFA were also used by $\mathrm{Yu}$ et al. (2010) in order to forecast the global generation of obsolete PCs.

Yoshida et al. (2009) employed MFA to estimate the percentages of flows of discarded computers in the different end of life options for the years 2000, 2001, and 2004, in Japan. Their research is based 
on the fact that the input amount in one process must be equal to the output amount from the next process. Published data from surveys and interviews were used to determine those flows. PC lifespan was approximated by the Weibull distribution and a nonlinear programming problem was solved to analyze the flows between the processes. Oguchi et al. (2008) attempted to find the amount of shipment and waste quantities in Japan for 94 durables (including ICT products) using product flow analysis. The lifespan was considered to follow the Weibull distribution, while domestic shipments for year 2003 were calculated using data from various industrial sources. Nguyen et al. (2009) applied the population balance model to forecast the waste quantities of five types of electronic appliances (color televisions, refrigerators, washing machines, air conditioners, and PCs) in Vietnam until 2025. This model is based on MFA and more specifically on the change of stock-in-use from one year to another. The variables used are the number of sales, stock in use (or number in possession), and the disposal ratio which is calculated using the Weibull distribution. The necessary for the estimations data, like average lifespan, use of home appliances, trends in purchases, and endof-life rates, were collected through a survey with questionnaires. The population balance model was also employed in the research of Kim et al. (2013), who estimated the amount of waste for eight electronic appliances in South Korea. In order to approximate lifespan of these appliances, the Weibull distribution was also chosen to be used. Furthermore, a survey was conducted to determine the products of every age owned per household, whereas other data like the number of households and domestic shipments were collected from other published sources. Their research resulted in the calculation of e-waste quantities for the period 2000-2020 and the collection rates for the years 20032009. The study of Polák and Drápalová (2012) focused on estimating the waste quantities of mobile phones in Czech Republic, using the so called 'distribution delay model'. Sales data for the period 1996-2010 were obtained from the country's statistical office, while for the period 1991-1995 were estimated. Future sales were forecasted using a logistic curve and the lifespan, including the hibernation period, was approximated by the Weibull distribution. The generation of mobile phones waste was estimated for the period 1995-2020, indicating a growing tendency. The method adopted by Walk (2009) was disposal analysis. In particular, 600 CRT devices that were collected at recycling centers in the region of Baden-Württemberg, Germany, constituted the sample data. The lifespan of the devices was considered to follow the Weibull distribution and the data for the devices in use were collected from reports and extrapolated to future estimations. The stock in use and the lifespan were combined with a technology substitution function to estimate the CRT devices to be discarded between 2000 and 2015.

Leigh et al. (2007) developed a model based on product flow analysis employing different discard rates and assuming that these rates are higher for business computers than for household computers. 
They estimated the total computer stock (for both businesses and households) in the Atlanta metropolitan area. In their study, Liu et al. (2006) predicted the amount of obsolete equipment for 5 kinds of electronic appliances in Beijing, China, using the market supply method and a questionnaire survey. A different approach was adopted by Pant (2013), who proposed a mathematical equation by incorporating sales, lifespan, and population statistics in order to estimate e-waste from a specific electronic item at local or global level.

A noteworthy classification of e-waste estimation methods was proposed by Wang et al. (2013). It classifies the existing methods into four categories: (i) disposal related analysis which includes field investigation in collection and treatment facilities, (ii) time series analysis which can be applied to forecast future quantities and fill incomplete datasets of the past, (iii) factor analysis, being the least used method, is based on the hypothetical causal relationships between exogenous factors, such as population size or income, and e-waste generation, and (iv) input-output analysis, being the most used method in multiple variations, evaluates the sources and final sinks of material flows. In their research, Wang et al. applied a variation of input-output analysis model to estimate e-waste amount in Netherlands with the goal to improve data quality for their estimations. Already published data of sales were used, in addition to data of stocks which were derived from other surveys. The Weibull distribution was used to approximate lifespan as exactly in previous studies. The classification of Wang et al. was adopted in the present study. Apart from the general category that each study belongs, we attempted to indicate the particular estimation methodology, the data used, and the findings of the study under examination. Table 1 summarizes the results of the literature review. 
Table 1. A list of selected recent articles on e-waste generation estimation

\begin{tabular}{|c|c|c|c|c|}
\hline Authors (year) & $\begin{array}{c}\text { Category of } \\
\text { evaluation }\end{array}$ & Data & Methodology & Findings \\
\hline Araújo et al. (2012) & Input-output analysis & $\begin{array}{c}\text { Refrigerators, } \\
\text { freezers, washing } \\
\text { machines, TVs, audio } \\
\text { systems, PCs, and } \\
\text { cell phones }\end{array}$ & $\begin{array}{l}\text { Consumption and use } \\
\text { (for mature markets) } \\
\text { and time step (for } \\
\text { non-mature markets) }\end{array}$ & $\begin{array}{l}\text { A model for e-waste } \\
\text { estimation in which } \\
\text { different methods are } \\
\text { used for mature and } \\
\text { non-mature markets }\end{array}$ \\
\hline $\begin{array}{c}\text { Dwivedy and Mittal } \\
(2010)\end{array}$ & $\begin{array}{c}\text { Time series and } \\
\text { input-output analysis }\end{array}$ & PCs & $\begin{array}{c}\text { Logistic model of PC } \\
\text { diffusion, MFA }\end{array}$ & $\begin{array}{c}\text { Estimation of e-waste } \\
\text { in India by } 2026\end{array}$ \\
\hline $\begin{array}{c}\text { Jain and Sareen } \\
(2006)\end{array}$ & $\begin{array}{l}\text { Input-output analysis } \\
\text { followed by disposal } \\
\text { analysis validation }\end{array}$ & PCs and TVs & $\begin{array}{c}\text { MFA, market supply } \\
\text { method, sensitivity } \\
\text { analysis }\end{array}$ & $\begin{array}{c}\text { Estimation of e-waste } \\
\text { in Delhi by } 2010\end{array}$ \\
\hline Kim et al. (2013) & Factor analysis & $\begin{array}{c}\text { Air conditioners, } \\
\text { microwave ovens, } \\
\text { mobile phones, TVs, } \\
\text { refrigerators, kimchi } \\
\text { refrigerators, vacuum } \\
\text { cleaners, and washing } \\
\text { machines }\end{array}$ & $\begin{array}{c}\text { Survey with } \\
\text { questionnaires, } \\
\text { population balance } \\
\text { model }\end{array}$ & $\begin{array}{l}\text { Estimation of e-waste } \\
\text { for } 8 \text { products in } \\
\text { South Korea, from } \\
2000 \text { to } 2020\end{array}$ \\
\hline $\begin{array}{c}\text { Kumar and Shrihari } \\
\text { (2007) }\end{array}$ & Input-output analysis & $\begin{array}{c}\text { PCs, TVs, } \\
\text { refrigerators, cell } \\
\text { phones, and washing } \\
\text { machines }\end{array}$ & $\begin{array}{c}\text { Market supply, } \\
\text { market supply A, and } \\
\text { consumption and use } \\
\text { method }\end{array}$ & $\begin{array}{l}\text { Estimation of e-waste } \\
\text { in the city of } \\
\text { Mangalore, India, for } \\
\text { the period 2006-2015 }\end{array}$ \\
\hline Leigh et al. (2007) & Input-output analysis & PCs & Product flow analysis & $\begin{array}{l}\text { Estimation of the } \\
\text { total computer stock } \\
\text { in the Atlanta } \\
\text { metropolitan area }\end{array}$ \\
\hline Liu et al. (2006) & Input-output analysis & $\begin{array}{c}\text { Color TV sets, } \\
\text { refrigerators, washing } \\
\text { machines, air } \\
\text { conditioners, PCs }\end{array}$ & $\begin{array}{l}\text { Market supply } \\
\text { method, survey with } \\
\text { questionnaires }\end{array}$ & $\begin{array}{c}\text { Prediction of obsolete } \\
\text { amount of household } \\
\text { appliances in Beijing, } \\
\text { China }\end{array}$ \\
\hline Nguyen et al. (2009) & Factor analysis & $\begin{array}{l}\text { Color TV sets, } \\
\text { refrigerators, washing } \\
\text { machines, air } \\
\text { conditioners, and PCs }\end{array}$ & $\begin{array}{c}\text { Survey with } \\
\text { questionnaires, } \\
\text { population balance } \\
\text { model }\end{array}$ & $\begin{array}{l}\text { Estimation of e-waste } \\
\text { in Vietnam by } 2025\end{array}$ \\
\hline Oguchi et al. (2008) & Input-output analysis & $\begin{array}{l}\text { Consumer durables } \\
\text { (including ICT } \\
\text { products) }\end{array}$ & Product flow analysis & $\begin{array}{c}\text { Estimation of the } \\
\text { product flow of } 94 \\
\text { consumer durables in } \\
\text { Japan }\end{array}$ \\
\hline Pant (2013) & $\begin{array}{l}\text { Time series and } \\
\text { factor analysis }\end{array}$ & $\begin{array}{l}\text { TVs, washing } \\
\text { machines, } \\
\text { refrigerators, } \\
\text { microwave ovens, air } \\
\text { conditioners, desktop } \\
\text { computers, and laptop } \\
\text { computers }\end{array}$ & $\begin{array}{l}\text { Formulation of } \\
\text { mathematical } \\
\text { relations }\end{array}$ & $\begin{array}{l}\text { A mathematical } \\
\text { equation for e-waste } \\
\text { estimation by } \\
\text { incorporating sales, } \\
\text { lifespan, and } \\
\text { population statistics }\end{array}$ \\
\hline $\begin{array}{l}\text { Polák and Drápalová } \\
\text { (2012) }\end{array}$ & Time series & Mobile phones & $\begin{array}{l}\text { Distribution delay } \\
\text { model }\end{array}$ & $\begin{array}{c}\text { E-waste generation of } \\
\text { mobile phones in } \\
\text { Czech Republic }\end{array}$ \\
\hline Steubing et al. (2010) & Input-output analysis & $\begin{array}{l}\text { PCs, CRT and LCD } \\
\text { monitors }\end{array}$ & MFA & $\begin{array}{c}\text { E-waste generation in } \\
\text { Chile from } 1996 \text { to } \\
2020 \\
\end{array}$ \\
\hline $\begin{array}{l}\text { Streicher-Porte et al. } \\
\text { (2005) }\end{array}$ & Input-output analysis & PCs & $\begin{array}{c}\text { Process-based MFA } \\
\text { and a field survey }\end{array}$ & $\begin{array}{l}\text { Investigation of the } \\
\text { economic drivers of } \\
\text { the recycling system }\end{array}$ \\
\hline Walk (2009) & Disposal analysis & CRT devices & Case study & $\begin{array}{l}\text { Estimation of the } \\
\text { CRT devices to be }\end{array}$ \\
\hline
\end{tabular}




\begin{tabular}{|c|c|c|c|c|}
\hline & & & & $\begin{array}{l}\text { discarded in Baden- } \\
\text { Württemberg, } \\
\text { Germany, between } \\
2000 \text { and } 2015\end{array}$ \\
\hline Wang et al. (2013) & Input-output analysis & $\begin{array}{l}\text { Washing machines, } \\
\text { laptop computers, } \\
\text { CRT TVs, and flat } \\
\text { panel TVs }\end{array}$ & $\begin{array}{l}\text { Multivariate input- } \\
\text { output analysis }\end{array}$ & $\begin{array}{l}\text { Techniques to } \\
\text { enhance data quality } \\
\text { in e-waste estimates }\end{array}$ \\
\hline $\begin{array}{l}\text { Yang and Williams } \\
(2009)\end{array}$ & Time series & PCs & $\begin{array}{c}\text { Logistic model of PC } \\
\text { diffusion }\end{array}$ & $\begin{array}{c}\text { Generation of } \\
\text { obsolete computers in } \\
\text { the U.S. }\end{array}$ \\
\hline Yoshida et al. (2009) & Input-output analysis & PCs & MFA & $\begin{array}{c}\text { Estimation of the } \\
\text { material flow of used } \\
\text { PCs in Japan }\end{array}$ \\
\hline Yu et al. (2010) & $\begin{array}{c}\text { Time series and } \\
\text { input-output analysis }\end{array}$ & PCs & Logistic model, MFA & $\begin{array}{l}\text { Investigation of } \\
\text { global trends in e- } \\
\text { waste generation }\end{array}$ \\
\hline Zhang et al. (2011) & Input-output analysis & $\begin{array}{l}\text { Air conditioners, } \\
\text { refrigerators, washing } \\
\text { machines, color TV } \\
\text { sets, and PCs }\end{array}$ & $\begin{array}{l}\text { MFA stock-based } \\
\text { model }\end{array}$ & $\begin{array}{l}\text { Prediction of obsolete } \\
\text { household appliances } \\
\text { in Nanjing, China, } \\
\text { from } 2009 \text { to } 2050\end{array}$ \\
\hline
\end{tabular}

It is obvious from the literature analysis that all estimation methods need the calculation of lifespan. The most prevalent ways are the following: (i) the interval between the purchases of new computers by the same owner, (ii) the time period that an individual or organization owns the computer, and (iii) the time period between the initial purchase of the computer and the final end-of-life management (Yang and Williams, 2009). After a certain period of use, a computer becomes obsolete and the owner has the following six options:

- resale/donation

- reuse

- storage

- recycling

- incineration

- landfill

However, only the last three are final end-of-life disposition options. But since there are three more options at an initial disposition stage, it is important to define the range of the computer's lifespan in a more practical way. To avoid dealing with quantities of unused computers which are stocked for a long time or obsolete ones which may be reused, but not with the same effectiveness as in their initial use, lifespan of a computer could be considered as the interval between the initial purchase of the computer and the time at which it is characterized as no more useful, out of operation or obsolete. According to the literature, there are two ways to approximate lifespan: (i) by applying an average lifespan to the estimation method, considering it, in this way, as constant and (ii) assuming that lifespan follows a statistical distribution like Normal, Lognormal or Weibull distribution. As we can 
see in the studies mentioned earlier, Weibull distribution is the most widely used approach in the estimation methods of ICT waste and has been proved to fit the data with the highest accuracy. For example, in the study of Gößling-Reisemann et al. (2009), the Normal, Lognormal, and Weibull distribution were tested with the aid of Kolmogorov-Smirnov test and Akaike's Information Criterion (AIC) (Akaike, 1973) for their fit, using data from recycling and collection stations in Bremen, Germany. Due to lack of data, the tests were applied only to printers waste and the results showed that Weibull distribution is more accurate approximation for the estimations, compared to the other two distributions which have been used in other relevant studies as well.

What is extracted from the literature review and needs to be stressed herein is that, lifespan is considered either to be constant or follow a specific distribution function irrespective of the geographic region that is examined. But, lifespan depends on the diffusion of the technology and various socio-economic factors which vary from one country/region to another (Rahman and Subramanian, 2012). This drawback of previous studies was the motivation of the proposed work.

\section{Mathematical model}

\subsection{Notation}

\section{Indices \\ i Country \\ $t, j \quad$ Time period}

\section{Parameters}

$S_{i}(t) \quad$ Cumulative sales of computers in $i$ country at time period $t$

$L_{i}(t) \quad$ Lifespan distribution in $i$ country at time period $t$

\section{Variables}

$O_{i}(t) \quad$ Number of obsolete computers in $i$ country at time period $t$

\subsection{Waste generation estimation model}

In this section, the mathematical formulation of the waste generation model will be presented. In order to compute the quantities of obsolete computers the proposed analysis is based on historical data of cumulative sales and on lifespan empirical distribution. The distribution function and corresponding parameters of computer's lifespan are extracted based on the work of Yu, Williams, $\mathrm{Ju}$, and Yang (2010). The selection of the most suited distribution was performed by testing the real 
data against the main continuous distributions. In this work, three goodness-of-fit criteria were taken into account in order to select the distribution with the best fitting, namely AIC, BIC (Schwarz, 1978), and Log-likelihood. A distribution is considered to fit best to the region's lifespan empirical distribution for minimum AIC and BIC values and for maximum Log-likelihood (minimum in absolute value), as shown in Tables $2-7$. The distribution which is presented in Tables $2-7$ concerns aggregated data for all countries which belong to the specific region. The distribution functions which fit aggregated data better for this region, are denoted with bold letters.

Table 2 Distribution fitting indices for Western Europe region

\begin{tabular}{lccc}
\hline Distribution & BIC & AIC & Log Likelihood \\
\hline Normal & 268,8036 & 263,5933 & $-129,7966$ \\
Weibull & $\mathbf{2 4 5 , 0 7 3 2}$ & $\mathbf{2 3 9 , 8 6 2 8}$ & $\mathbf{- 1 1 7 , 9 3 1 4}$ \\
Log Normal & 301,9352 & 296,7249 & $-146,3624$ \\
Cauchy & 292,2698 & 287,0594 & $-141,5297$ \\
Logistic & 274,8877 & 269,6773 & $-132,8387$ \\
Exponential & 511,2764 & 508,6713 & $-253,3356$ \\
\hline
\end{tabular}

Table 3 Distribution fitting indices for Eastern Europe region

\begin{tabular}{lccc}
\hline Distribution & BIC & AIC & Log Likelihood \\
\hline Normal & 302,0187 & 296,8083 & $-146,404$ \\
Weibull & $\mathbf{2 8 8 , 9 8 6 9}$ & $\mathbf{2 8 3 , 7 7 6 6}$ & $\mathbf{- 1 3 9 , 8 8 8}$ \\
Log Normal & 335,5344 & 330,3241 & $-163,162$ \\
Cauchy & 300,4287 & 295,2184 & $-145,609$ \\
Logistic & 298,4901 & 293,2797 & $-144,64$ \\
Exponential & 528,7593 & 526,1542 & $-262,077$ \\
\hline
\end{tabular}

Table 4 Distribution fitting indices for North America region

\begin{tabular}{lccc}
\hline Distribution & BIC & AIC & Log Likelihood \\
\hline Normal & 333,1705 & 327,9602 & $-161,98$ \\
Weibull & $\mathbf{3 2 9 , 2 4 8 6}$ & $\mathbf{3 2 4 , 0 3 8 3}$ & $\mathbf{- 1 6 0 , 0 1 9}$ \\
Log Normal & 370,5075 & 365,2972 & $-180,649$ \\
Cauchy & 379,0086 & 373,7982 & $-184,899$ \\
Logistic & 341,6091 & 336,3988 & $-166,199$ \\
Exponential & 480,8522 & 478,247 & $-238,124$ \\
\hline
\end{tabular}

Table 5 Distribution fitting indices for South/Middle America region

\begin{tabular}{lccc}
\hline Distribution & BIC & AIC & Log Likelihood \\
\hline Normal & 244,0753 & 238,865 & $-117,433$ \\
Weibull & $\mathbf{2 2 6 , 3 1 3 3}$ & $\mathbf{2 2 1 , 1 0 2 9}$ & $\mathbf{- 1 0 8 , 5 5 2}$ \\
Log Normal & 255,9641 & 250,7537 & $-123,377$
\end{tabular}




\begin{tabular}{llll} 
Cauchy & 299,2935 & 294,0832 & $-145,042$ \\
Logistic & 259,0419 & 253,8316 & $-124,916$ \\
Exponential & 550,5735 & 547,9683 & $-272,984$ \\
\hline
\end{tabular}

Table 6 Distribution fitting indices for Asia/Pacific region

\begin{tabular}{lccc}
\hline Distribution & BIC & AIC & Log Likelihood \\
\hline Normal & $\mathbf{1 7 0 , 4 4 4 3}$ & $\mathbf{1 6 5 , 2 3 4}$ & $\mathbf{- 8 0 , 6 1 7}$ \\
Weibull & 178,006 & 172,7957 & $-84,3978$ \\
Log Normal & 173,1545 & 167,9442 & $-81,9721$ \\
Cauchy & N/A & N/A & N/A \\
Logistic & 178,995 & 173,7846 & $-84,8923$ \\
Exponential & 533,8199 & 531,2148 & $-264,607$ \\
\hline
\end{tabular}

Table 7 Distribution fitting indices for region of Japan, Australia and New Zealand

\begin{tabular}{lccc}
\hline Distribution & BIC & AIC & Log Likelihood \\
\hline Normal & 237,7638 & 232,5535 & $-114,277$ \\
Weibull & $\mathbf{2 1 7 , 5 9 4 8}$ & $\mathbf{2 1 2 , 3 8 4 5}$ & $\mathbf{- 1 0 4 , 1 9 2}$ \\
Log Normal & 271,3503 & 266,14 & $-131,07$ \\
Cauchy & 275,4377 & 270,2273 & $-133,114$ \\
Logistic & 238,3568 & 233,1465 & $-114,573$ \\
Exponential & 509,4874 & 506,8822 & $-252,441$ \\
\hline
\end{tabular}

A perusal of Tables $2-7$ shows that the best fitted distribution in most of the examined regions (Western and Eastern Europe, North and South/Middle America, and Australia/New Zealand/Japan) is Weibull with the exception of the region of Asia/Pacific where the most appropriate distribution is Normal. Exact parameter values for each instance were derived using Maximum Likelihood Estimation (MLE) method with fitdistrplus R-package (Delignette-Muller et al., 2013). Distribution and curve fitting is generally a commonly used analysis in the estimation and projection of e-waste generation quantities (Dwivedy and Mittal, 2010; Pant, 2013). In Figures 2 - 4, the Probability Density Functions (PDF) are presented for each of the empirical distributions of the lifespan. The estimated parameters of each selected distribution are presented in Table 8, along with the PDF of each distribution. 
Table 8 Parameters of the fitted distributions for all regions

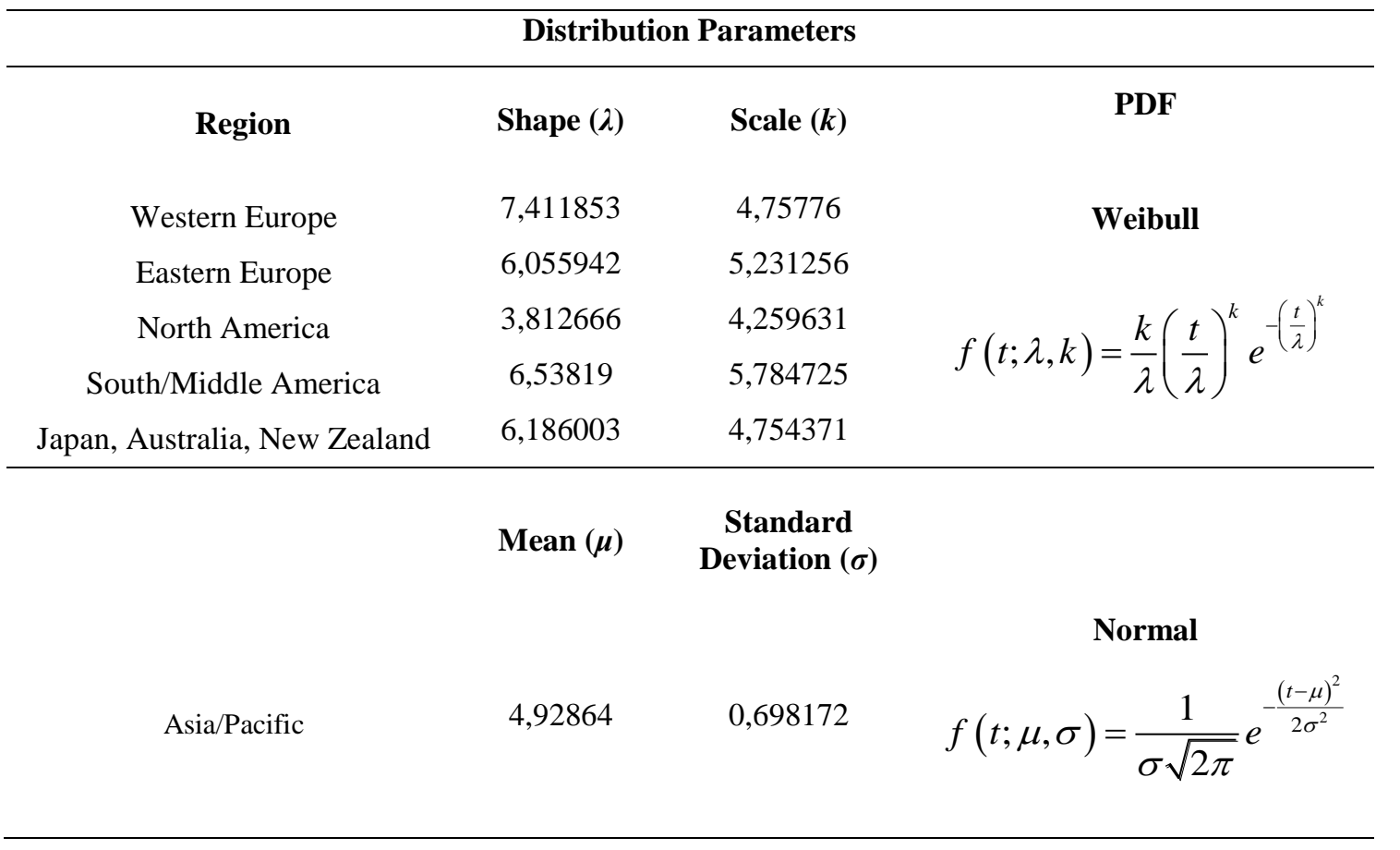

From each of the aforementioned regions, computer sales are collected from leading countries ${ }^{2}$ (Kotabe, 2002). The obsolete computer quantities are calculated based on equation (1) (Yu et al., 2010; Dwivedy and Mittal, 2010; Wang et al., 2013).

$$
O_{i}(t)=\sum_{j<t} S_{i}(t-j) \cdot L_{i}(j)
$$

Based on (1), the cumulative sales are summed up to the current period and are multiplied with the lifespan PDF for time period $j$. The output of this formula is the cumulative obsolete computer quantities for time period $t$ and for country $i$.

The countries taken from each region are:

- Western Europe: France, United Kingdom, Germany, Denmark, Italy, Norway, Sweden, Finland

- Eastern Europe: Greece, Poland, Hungary, Czech Republic, Bulgaria, Estonia, Lithuania, Latvia, Slovakia

- Asia/Pacific: Hong Kong, Singapore, South Korea, Iran, China, Indonesia, Malaysia, Taiwan

- Japan, Australia, New Zealand

- North America: Canada, USA

\footnotetext{
${ }^{2}$ Some countries which are considered to be leading in a specific area may not appear due to lack of data
} 
- Middle/South America: Mexico, Uruguay, Argentina, Brazil.

As previously mentioned, the obsolete computer quantities are calculated based on sold quantities and the probability that a computer is characterized as obsolete or discarded after $j$ years. Based on this approach, customization per region and per country can be achieved as the formula computes the quantities per region in the world, considering lifespan distribution different unlike the works that have been proposed in the literature until now. The estimation of obsolete computer quantities is performed with GAMS software (McCarl, 2003) (see Appendix).

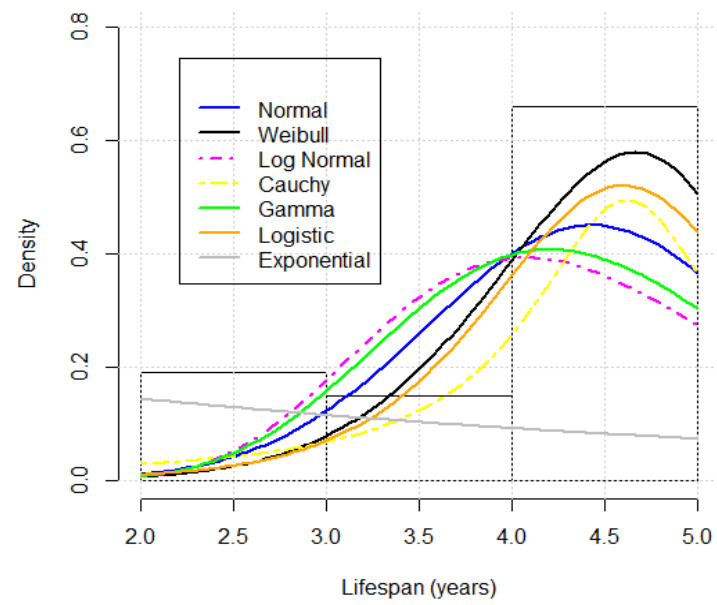

a)

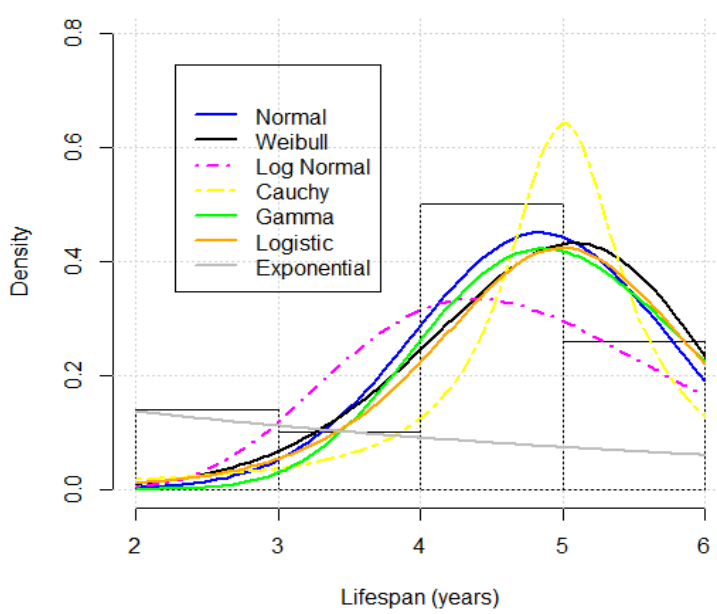

b)

Figure 2 Distribution fitting for the lifespan distribution of a) Western Europe, b) Eastern Europe.

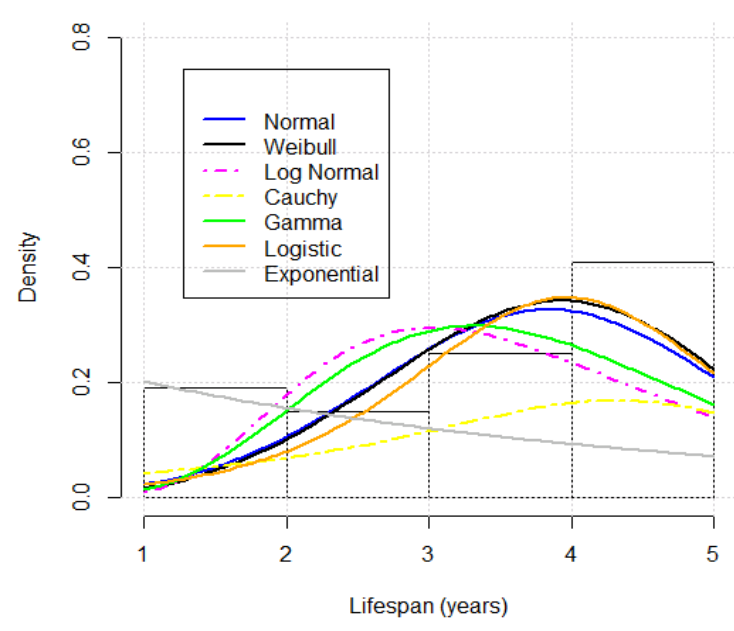

c)

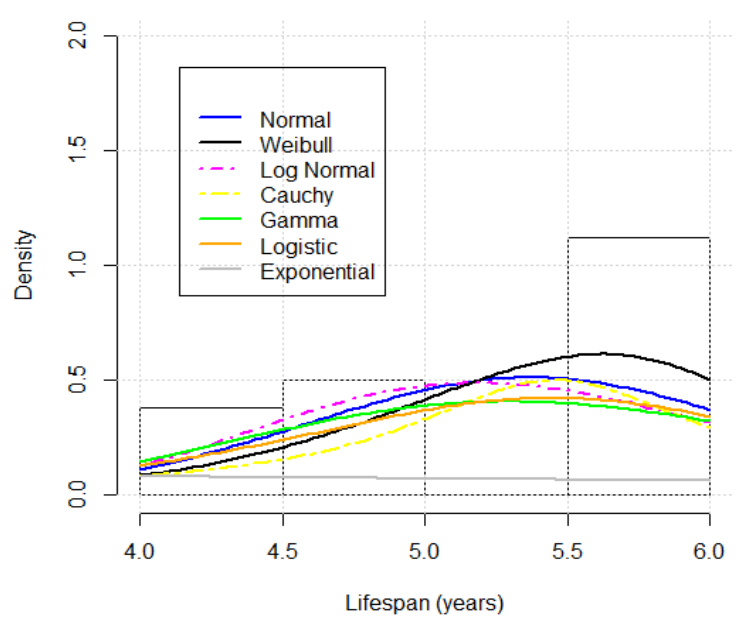

d) 


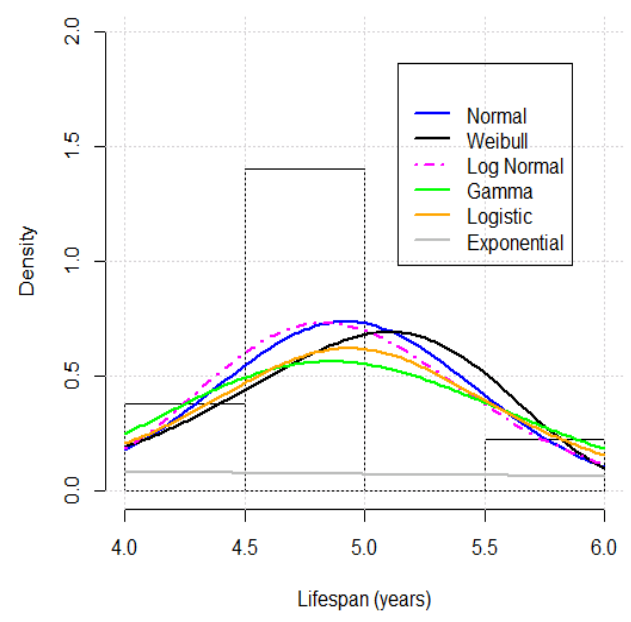

e)

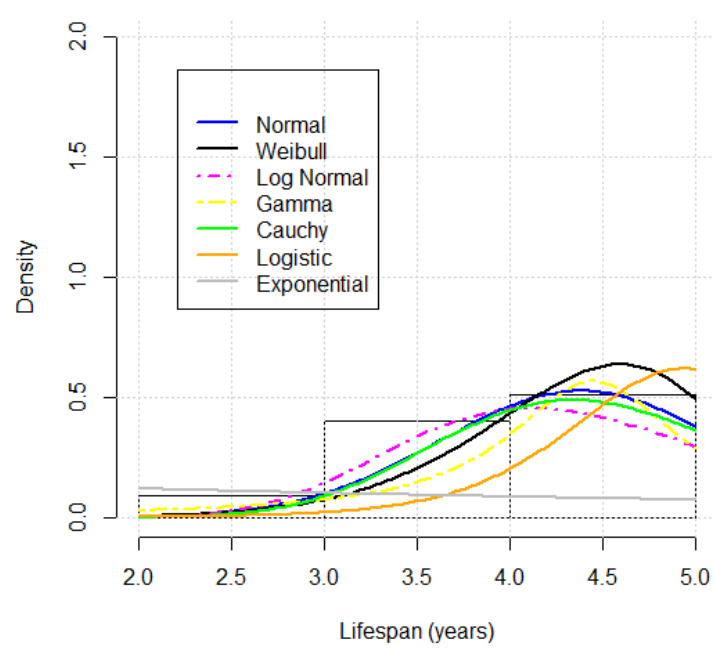

f)

Figure 4 Distribution fitting for the lifespan distribution of e) Asia/Pacific, f) Japan, Australia, and New Zealand.

\subsection{E-waste forecasting models}

In this section, the models which are used to evaluate the out of sample forecasted e-waste generation quantities are described. Several regressions are deployed in order to deeply investigate the one which converges to the true quantity of e-waste more accurately. The models can be separated into three large categories: dynamic regressions (time-varying coefficient models), autoregressive models, and trend models.

\subsubsection{Dynamic regressions}

These models are usually presented in state space notation. Based on the notion that coefficients are not constant over time, especially when series are characterized by violent structural breaks, linear regressions with time - varying parameters provide great solution when forecasting is concerned. The first model which is applied is the so called local level model (Hyndman and Khandakar, 2007). The observation equation consists of a stochastic random - walk while the state (or update) equation encompasses time - varying intercept term. The disturbances in both equations are assumed to be normally distributed. 


$$
\begin{array}{ll}
\text { Observation Equation } & y_{t}=\mu_{t}+e_{t}, e_{t} \sim N\left(0, \sigma_{e_{t}}^{2}\right) \\
\text { State Equation } & \mu_{t}=\mu_{t-1}+u_{t}, u_{t} \sim N\left(0, \sigma_{u_{t}}^{2}\right)
\end{array}
$$

Parameters $\mu_{t}, \sigma_{e_{t}}^{2}$ and $\sigma_{u_{t}}^{2}$ are estimated using maximum likelihood method. In the case when another parameter is added in the model, it incorporates more information of the unknown variability of dependent covariate and the model is called local - level trend (Makridakis et al., 2008). The observation equation of such models includes a slope coefficient except for constant term and two state equations, assuming Gaussian white noises. Furthermore, all disturbances are independent to lags or leads and this hypothesis ensures the exogeneity of the models.

$$
\begin{array}{ll}
\text { Observation Equation } & y_{t}=\mu_{t}+b_{t}+e_{t}, e_{t} \sim N\left(0, \sigma_{e_{t}}^{2}\right) \\
\text { State Equation } & \mu_{t}=\mu_{t-1}+u_{t}, u_{t} \sim N\left(0, \sigma_{u_{t}}^{2}\right) \\
\text { State Equation } & b_{t}=b_{t-1}+\xi_{t}, \xi_{t} \sim N\left(0, \sigma_{\xi_{t}}^{2}\right)
\end{array}
$$

Exponential smoothing is a flexible form of dynamic models, which incorporates seasonality. Several versions have been proposed in the relative literature and concern the method by which error term is incorporated in the forecasting equation (Hyndman et al., 2002). The model with additive trend and error term can be written in state - space notation as:

$$
\begin{array}{lc}
\text { Observation Equation } & \mu_{t}=l_{t-1}+b_{t-1} \\
\text { State Equation } & l_{t}=l_{t-1}+b_{t-1}+e_{t}, e_{t} \sim N\left(0, \sigma_{e_{t}}^{2}\right) \\
\text { State Equation } & b_{t}=b_{t-1}+a \cdot e_{t}
\end{array}
$$

where $\alpha, \beta$ are constants. In the case of an additive error model where trend is introduced in the state equation multiplicatively, the model can be altered into the following state - space representation:

$$
\begin{array}{lc}
\text { Observation Equation } & \mu_{t} e_{t}=l_{t-1} \cdot b_{t-1}, e_{t} \sim N\left(0, \sigma_{e_{t}}^{2}\right) \\
\text { State Equation } & y_{t}=l_{t-1} \cdot b_{t-1}+e_{t}, e_{t} \square N\left(0, \sigma_{e_{t}}^{2}\right) \\
\text { State Equation } & b_{t}=b_{t-1}+\frac{a \cdot \beta \cdot e_{t}}{l_{t-1}}
\end{array}
$$


In this study, the best exponential smoothing model variation is chosen based on the AIC criterion, which is generally preferred against other selection methods, due to the fact that it penalizes models with many parameters.

\subsubsection{Autoregressive models}

The growth models have been widely used in many scientific fields, especially in marketing research in order to provide intuition about the maximum market potential as well as adoption dynamics. Bass (1969) model is the first and mostly utilized equation, due to its flexibility and ability to adjust to cumulative sales data without the use of explanatory variables (Bass et al., 1994). In addition, another advantage of Bass model lies in the fact that its parameters are easily interpretable. Let $F(t)$ be the cumulative sales at time $t, F(t-1)$ be the cumulative sales at time $t-1, p$ the coefficient of innovation, $q$ the coefficient of imitation, and $m$ a parameter which denotes the maximum penetration level; Bass model can be written as:

$$
F(t)=F(t-1)+\left[p+\frac{q}{m} \cdot F(t-1)\right] \cdot[m-F(t-1)]
$$

Box-Jenkins method (Anderson, 1976) has been proved to be a useful tool for predicting almost any set of data. The combination of $p$ order autoregressive models along with $q$ order moving average integrated at $d$ degree produce the $\operatorname{ARIMA}(p, d, q)$ model. In a general form, an integrated of zero degree $(\mathrm{d}=0)$ ARMA model, can be presented as:

$$
\begin{aligned}
& Y_{t}=\underbrace{\mu+\underbrace{\sum_{i=1}^{p} a_{i} \cdot Y_{t-i}+\varepsilon_{t}}_{i=1}+\underbrace{\sum_{j=1}^{q} \theta_{j} \cdot \varepsilon_{t-j}}_{M A(q)}}_{A R(p)} \\
& \varepsilon_{t} \sim N\left(0, \sigma_{\varepsilon_{t}}^{2}\right)
\end{aligned}
$$

The selection of the order of autoregressive model (p), as well as of the moving average component (q) is based on the value of AIC criterion.

\subsubsection{Trend Models}

Except for Bass model, the Gompertz model is implemented as well. Having been initially deployed in order to describe mortality rates, Gompertz is utilized in forecasting sales of telecommunication products (e.g. Christodoulos et al., 2010). Keeping the same notation for cumulative sales and maximum potential parameter as before and denoting as $a$ and $b$ two strictly non-negative 
coefficients, which are related to the time point at which diffusion reaches $37 \%$ of its upper level and the speed of adoption sales respectively, Gompertz is given below (Michalakelis et al., 2008):

$$
F(t)=m \cdot e^{-a \cdot e^{-b \cdot t}}
$$

Last but not least, Fisher - Pry (1971) model is implemented. This model bears great resemblance to the simple logistic curve, with the difference that a saturation level parameter $(m)$ is added multiplicatively. Its parameters $a$ and $b$ provide information concerning how quickly product's diffusion evolves.

$$
F(t)=\frac{m}{1+e^{-(a+b \cdot t)}}
$$

\subsection{Forecasting evaluation}

In order to assess the out-of-sample forecasting accuracy of the employed models, two measures are utilized. The first is the Mean Absolute Error (MAE), which is a scale dependent measure for error forecasting. Let $Y_{t}$ be the observed cumulative quantity of obsolete PCs at time $t$, while $F_{t}$ denotes the forecasted value; MAE is given as follows:

$$
M A E=\sum_{t=T}^{T+h} \frac{\left|Y_{t}-F_{t}\right|}{h}
$$

In (17), $h$ represents the forecast horizon. Absolute values are used so that offsetting of errors due to opposite signs is possible (Hyndman, 2006). The second measure which has been used to validate the forecasting accuracy of the models is the Mean Square Error (MSE). Keeping the same notation as above, MSE can be mathematically formulated as:

$$
M S E=\sum_{t=T}^{T+h} \frac{\left(Y_{t}-F_{t}\right)^{2}}{h}
$$

The MSE is an alternative measure of MAE, which may lead to inflated results compared to MAE.

\begin{tabular}{|c|c|c|c|c|c|c|c|c|c|c|c|c|c|c|}
\hline \multirow[b]{2}{*}{ Region } & \multicolumn{2}{|c|}{ Bass } & \multicolumn{2}{|c|}{ Gompertz } & \multicolumn{2}{|c|}{ Logistic } & \multicolumn{2}{|c|}{ Trend model } & \multicolumn{2}{|c|}{ Level model } & \multicolumn{2}{|c|}{ ARMA } & \multicolumn{2}{|c|}{ Exponential Smoothing } \\
\hline & MAE & MSE & MAE & MSE & MAE & MSE & MAE & MSE & MAE & MSE & MAE & MSE & MAE & MSE \\
\hline
\end{tabular}
This measure penalizes the absolute distance between observed and forecasted values. The forecast horizon chosen is 5 years.

Table 9 Forecast errors (\%) for each geographic region 


\begin{tabular}{|c|c|c|c|c|c|c|c|c|c|c|c|c|c|c|}
\hline \multicolumn{15}{|c|}{ Western Europe } \\
\hline Denmark & 0.12 & 0.0002 & 0.95 & 0.013 & 0.94 & 0.013 & 0.008 & 9E-06 & 1.45 & 0.025 & 0.17 & 0.0005 & 0.008 & 9E-06 \\
\hline Finland & 0.5 & 0.002 & 1.56 & 0.037 & 1.54 & 0.036 & 0.006 & $8 \mathrm{E}-05$ & 2.45 & 0.072 & 0.16 & 0.0004 & $0.006^{*}$ & $8 E-05^{*}$ \\
\hline France & 0.007 & $5 \mathrm{E}-05$ & 0.018 & 0.0004 & 0.017 & 4E-04 & 0.001 & $2 \mathrm{E}-06$ & 0.027 & $9 \mathrm{E}-04$ & $8 \mathrm{E}-05$ & $1 \mathrm{E}-07$ & 2E-05 & 3E-07 \\
\hline Germany & 0.08 & 0.001 & 0.52 & 0.0045 & 0.51 & 0.004 & 0.4 & 0.0026 & 1.16 & 0.015 & 0.87 & 0.011 & 0.33 & 0.0018 \\
\hline Italy & 0.82 & 0.006 & 1.8 & 0.05 & 1.78 & 0.05 & 0.35 & 0.002 & 3.21 & 0.12 & 0.26 & 0.001 & 0.35 & 0.0023 \\
\hline Norway & 1.03 & 0.015 & 9.3 & 1.27 & 9.24 & 1.25 & 2.65 & 0.11 & 11.83 & 1.8 & 1.59 & 0.029 & 2.65 & 0.11 \\
\hline Sweden & 1.07 & 0.017 & 4.86 & 0.35 & 4.8 & 0.34 & 1.57 & 0.03 & 6.89 & 0.59 & 0.94 & 0.02 & 1.58 & 0.03 \\
\hline UK & 0.88 & 0.011 & 7.43 & 0.83 & 7.38 & 0.81 & 0.31 & 0.0011 & 11.25 & 1.54 & 0.89 & 0.012 & 0.31 & 0.001 \\
\hline \multicolumn{15}{|c|}{ Eastern Europe } \\
\hline Estonia & 5.71 & 0.46 & 18.83 & 5.51 & 18.77 & 5.47 & 1.32 & 0.022 & 31.67 & 11.99 & 1.32 & 0.022 & 19.73 & 6.77 \\
\hline Greece & 5.65 & 0.32 & 14.07 & 2.89 & 14.02 & 2.87 & 0.68 & 0.007 & 19.41 & 4.68 & 1.67 & 0.032 & 9.47 & 1.33 \\
\hline Latvia & 6.89 & 0.65 & 22.73 & 8.05 & 22.67 & 8.01 & 8.03 & 0.78 & 36.23 & 16.02 & 3.19 & 0.26 & 19.38 & 7.22 \\
\hline Lithuania & 7.32 & 0.74 & 20.33 & 6.39 & 20.27 & 6.35 & 2.61 & 0.07 & 33.22 & 13.3 & 2.62 & 0.08 & 30.57 & 16.45 \\
\hline \multicolumn{15}{|c|}{ Asia/Pacific } \\
\hline China & 0.006 & $6 \mathrm{E}-05$ & 0.07 & 5E-05 & 0.38 & 0.002 & 0.005 & $4 \mathrm{E}-05$ & 0.61 & 0.004 & 2E-04 & 8E-08 & 0.0027 & $8 \mathrm{E}-07$ \\
\hline Indonesia & 0.93 & 0.013 & 5.53 & 0.47 & 5.47 & 0.46 & 1.74 & 0.04 & 9.4 & 1.05 & 0.36 & 0.002 & 1.74 & 0.04 \\
\hline Iran & 1.37 & 0.027 & 10.26 & 1.56 & 10.21 & 1.54 & 1.11 & 0.019 & 14.54 & 2.62 & 0.58 & 0.006 & 1.12 & 0.019 \\
\hline Malaysia & 1.15 & 0.019 & 7.17 & 0.77 & 7.11 & 0.76 & 0.84 & 0.01 & 11.23 & 1.52 & 0.002 & 2E-05 & 0.84 & 0.01 \\
\hline Taiwan & 0.94 & 0.013 & 25.96 & 6.7 & 5.27 & 0.42 & 1.51 & 0.031 & 8.78 & 0.92 & 0.51 & 0.005 & 1.16 & 0.02 \\
\hline \multicolumn{15}{|c|}{ Japan,Australia } \\
\hline Australia & 0.61 & 0.005 & 3.75 & 0.21 & 3.72 & 0.2 & 0.17 & 0.0005 & 5.49 & 0.37 & 0.16 & 2E-04 & 0.16 & 0.0005 \\
\hline Japan & 0.48 & 0.002 & 1.77 & 0.048 & 1.75 & 0.047 & 0.48 & 0.003 & 2.94 & 0.1 & 0.28 & 0.014 & 0.48 & 0.003 \\
\hline \multicolumn{15}{|c|}{ North America } \\
\hline Canada & 1.61 & 0.02 & 4.81 & 0.35 & 4.75 & 0.34 & 0.78 & 0.0085 & 7.53 & 0.68 & 0.15 & 3E-04 & 0.86 & 0.01 \\
\hline USA & 2.11 & 0.004 & 2.82 & 0.13 & 2.78 & 0.12 & 0.74 & 0.011 & 5.61 & 0.37 & 0.79 & 0.014 & 2.1 & 0.064 \\
\hline \multicolumn{15}{|c|}{ Central/South America } \\
\hline Argentina & 2.57 & 0.09 & 2.68 & 0.08 & 10.34 & 1.54 & 1.91 & 0.04 & 14.59 & 2.61 & 1.06 & 0.04 & 1.92 & 0.05 \\
\hline Brazil & 2.62 & 0.09 & 13.71 & 2.71 & 13.67 & 2.68 & 5.31 & 0.43 & 16.35 & 3.5 & 2.35 & 0.09 & 1.36 & 0.027 \\
\hline Mexico & 2.31 & 0.07 & 8.8 & 1.12 & 8.77 & 1.11 & 0.46 & 0.003 & 11.67 & 1.71 & 0.93 & 0.019 & 3.08 & 0.11 \\
\hline Urugay & 2.56 & 0.08 & 20.35 & 5.77 & 20.31 & 5.74 & 10.47 & 1.91 & 18.48 & 5.04 & 6.52 & 0.81 & 8.81 & 1.42 \\
\hline
\end{tabular}

\section{Results}


In 16 out of 25 cases, ARMA model exhibits more accurate forecasts compared to the other models. In the rest 9 cases, Kalman trend, exponential smoothing, and Bass model outperform the non-linear trend models (e.g. Gompertz, Simple Logistic, and Kalman level model). ARMA's forecasting superiority is due to the fact that this model is parsimonious. As a result, it is easier to compute and interpret forecasts which are less sensitive to deviations between parameters and estimates. Another reason why ARMA models tend to produce more accurate forecasts compared to other models is that the time series are monotonically increasing. Trend models' forecast values do not seem to describe adequately the process by which PCs become obsolete through time. Based on Table 9, remarkable is the fact that throughout all countries which belong to the Asia/Pacific geographic region, ARMA model exhibits the minimum forecast error. The employed models perform actually zero forecast errors (MAE and MSE). The range of forecasting models offers great alternatives to encompass the dynamics of procedure by which computers become obsolete in each country. ARMA models are proved to be a very useful tool for forecasting the cumulative amount of obsolete computers for many countries, exhibiting forecast errors which are approximately zero. The dynamic regression model with a trend term describes adequately the process in 6 out of 25 countries of the sample while the level model (dynamic regression which includes only intercept) does not seem to capture the variations of obsolesce procedure across different countries and geographic regions. The trend models (Logistic and Gompertz), which have been widely used as a means of forecasting obsolete amount of ICT products (e.g. Yang and Williams, 2009; Yu et al., 2010), fail to accurately predict the actual values in sample, that is partially due to their sensitivity to initial conditions. On the other hand, non - linear autoregressive models (e.g. Bass), which have been frequently used in explaining diffusion process of ICT products, achieved the least forecast error compared to the other models, in 3 out of 25 cases. Overall, across all countries and models, the minimum value of MAE and MSE observed was $2 \mathrm{E}-04 \%$ and $8 \mathrm{E}-08 \%$ correspondingly, while the largest errors that were reported were $3.19 \%$ and $0.26 \%$. Considering the case of Estonia, the trend dynamic linear model (Trend Model) and ARMA process seem to perform the least forecast errors (MAE and MSE) compared to the other used equation. This finding is attributed to the flexibility of trend models to incorporate the upward move in time series, as well as the ARMA process does. 


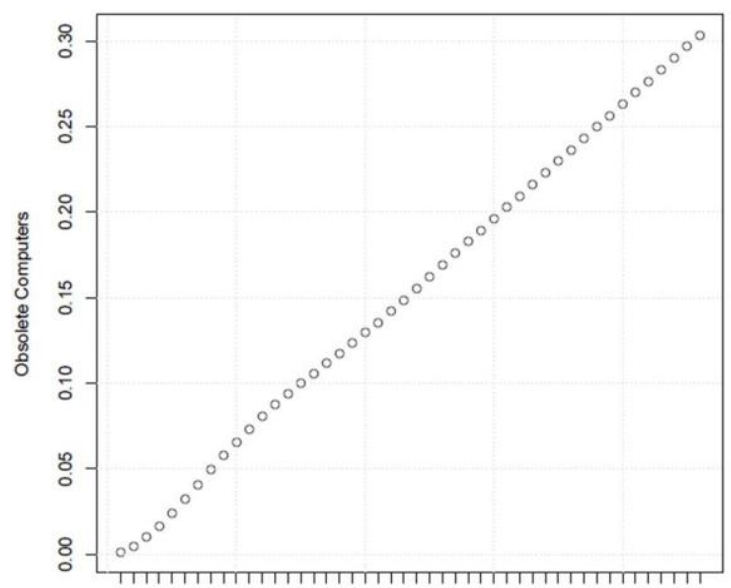

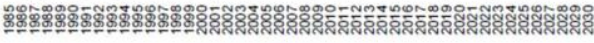

Years

(a)

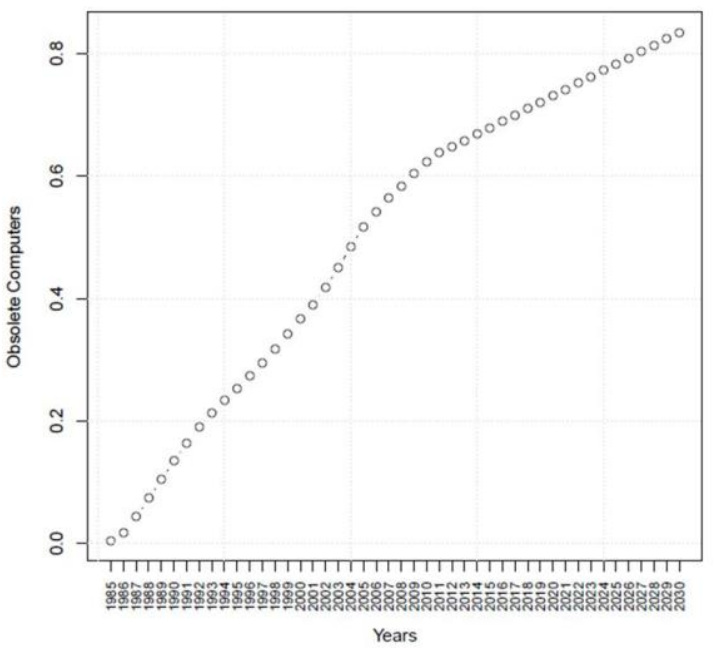

(c)

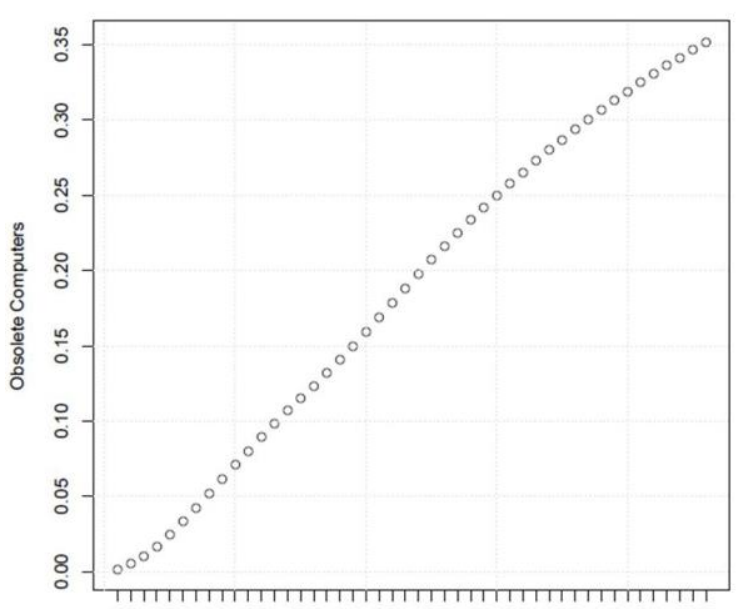

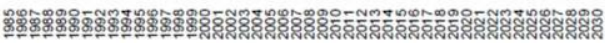
Years

(b)

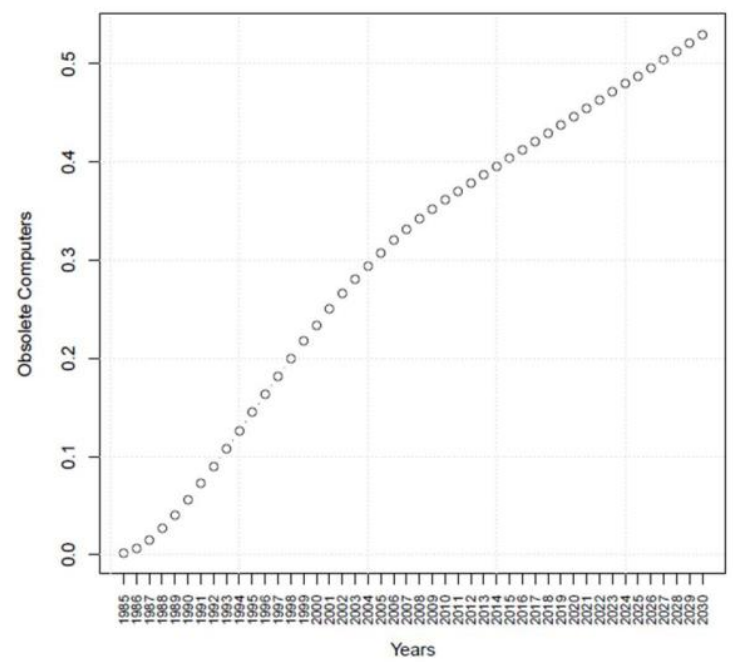

(d) 


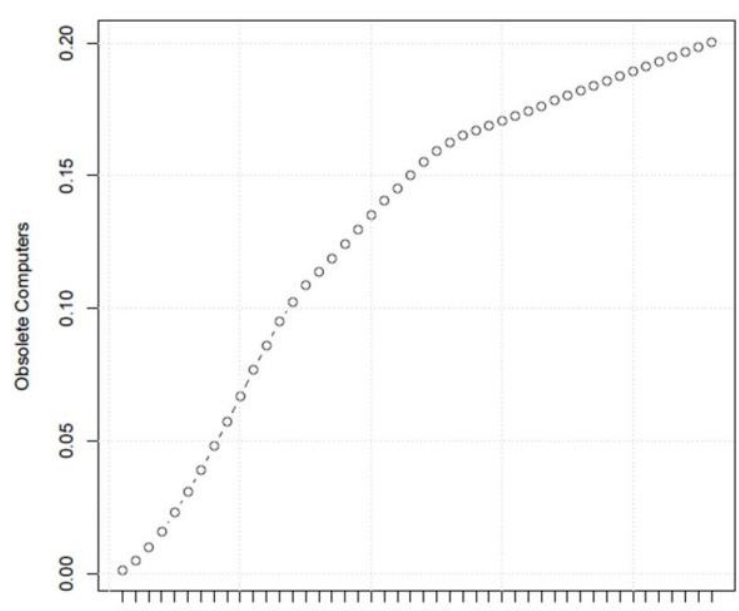

:

Years

$(e)$

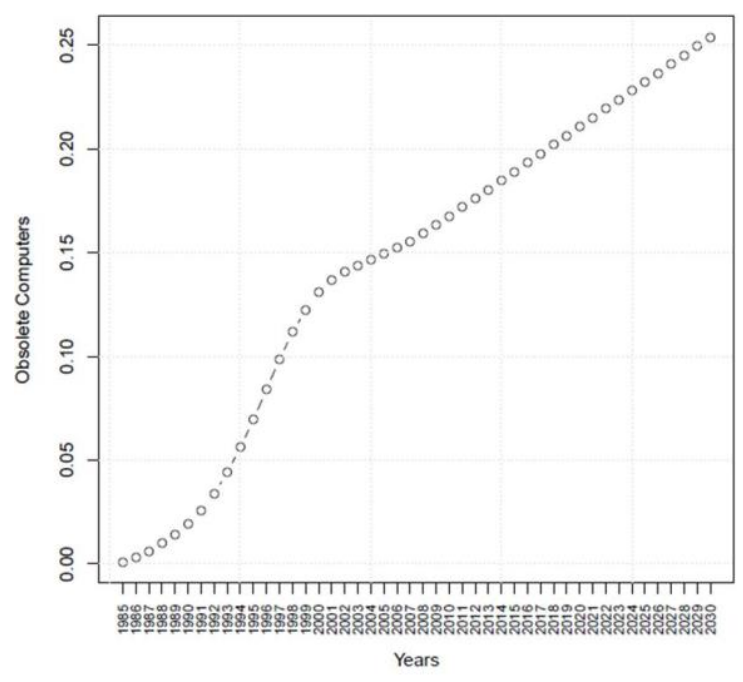

$(f)$

Figure 5 Forecasted cumulative obsolete computers per household and per year for $a$ ) United Kingdom, $b$ ) France, $c$ ) USA, $d$ ) Japan, $e$ ) Germany, $f$ ) Sweden.

Using the employed models, an attempt for long - run forecasting was conducted. The forecasting horizon is 18 years ahead. The evolution of obsolete computers for United Kingdom presents an upward tendency (Figure 4a) reaching a maximum value of approximately 0.3 in year 2030, while France is assumed to discard 5\% more amount per household by the end of the same year (Figure 4b). On the other hand, the USA, which is a representative country of the North American group, is expected to discard nearly $80 \%$ of the total amount of computers by 2030 (Figure 4c), while Japan $50 \%$. Germany and Sweden perform similar patterns about the amount of obsolete computers which are discarded (Figure 4e and Figure 4f). By 2030, about $25 \%$ of the maximum potential will not be in use. Australia, by the end of 2030, will have discarded more than $80 \%$ of the computers in use, while the percentage of obsolete computers in Denmark will reach approximately at $24 \%$, while Finland on the other hand will discard 35\% of PCs by 2030.

\subsection{Policy Implications}

We believe that this study has significant implications in order to develop appropriate e-waste policies. The estimation of future computer waste quantities (particularly in the long run) is a prerequisite to better organize collection and treatment processes, and build the appropriate infrastructure. Regarding e-waste collection, policymakers and managers could estimate the required capacity of collection facilities, determine rationally the collection points, and schedule the necessary 
operations. With respect to e-waste treatment, they could better manage transportation operations and opt for more suitable end-of-life options (e.g. recycling).

Another key policy implication of this study is that computer manufacturers could more effectively plan their activities since they will be aware of the time and the percentage that their products will be discarded. Such activities are the design of new product models, the development of marketing strategies, as well as the provision of incentives to households and enterprises to return their WEEE. It is true that there are a lot of opportunities to mitigate environmental, economic, and social impacts of e-waste generation. However, a serious rethinking of e-waste policies is needed; and the first step to this direction is estimating as accurately as possible e-waste quantities. It is true that the tremendous production of e-waste is not only due to increased computer (or any other ICT equipment) sales. There are also a lot of social, cultural, behavioral, economic, and environmental factors, which need to be further analyzed. This analysis is beyond the scope of this paper; however, emphasis is given on this point since the information that will be derived from this analysis could be used to explain the size and the variability of future e-waste quantities. Therefore, the proposed model sets the foundations for subsequent studies in order to investigate the major factors that influence the continuously increasing generation of WEEE worldwide.

\section{Discussion}

Technology diffusion is one of the major features of this decade. The introduction of new technology into everyday use appliances (computers, tablets, mobile phones, etc.) leads to the increase of sales and change of the modern attitude of life. Nevertheless, new devices with better software and hardware characteristics force obsolete devices out of use (to become either stock or recycled). The previous statement suggests that the computer's lifespan has been radically decreased. However, due to different socio-economic environment, lifespan differs among countries or regions in the same continent (West and East Europe). Besides the estimation of the current state of e-waste, it is of great importance to examine the future generation providing a tool for e-waste handling policy. Thus, the springboard for the estimation of e-waste quantities has deeper roots than just the application of a forecasting technique to the sold quantities.

In this work, a holistic view of the global e-waste generation is presented. The lifespan PDF differs on distribution type in different regions of the world, and thus the expected e-waste quantities are customized for each country/region of the world. Lifespan distribution was selected among a predetermined set of PDFs, namely Normal, Weibull, LogNormal, Cauchy, Logistic, and Exponential, based on PDF fit indices (AIC, BIC, Log-Likelihood). The aforementioned PDFs were chosen based 
on previous studies in the relevant literature. Furthermore, a selection of advanced forecasting methods have been employed and based on in-sample fit indices (MAE, MSE), the best technique was selected for out-of sample forecasting. Results demonstrate upward curves in developed countries (e.g. USA, UK, and Japan) regardless the fact that they belong to three different regions of the world, as examined in the present work. In total, $25 \%$ of sold computers will not be in use by 2030.

The proposed approach is graphically presented in Figure 6.

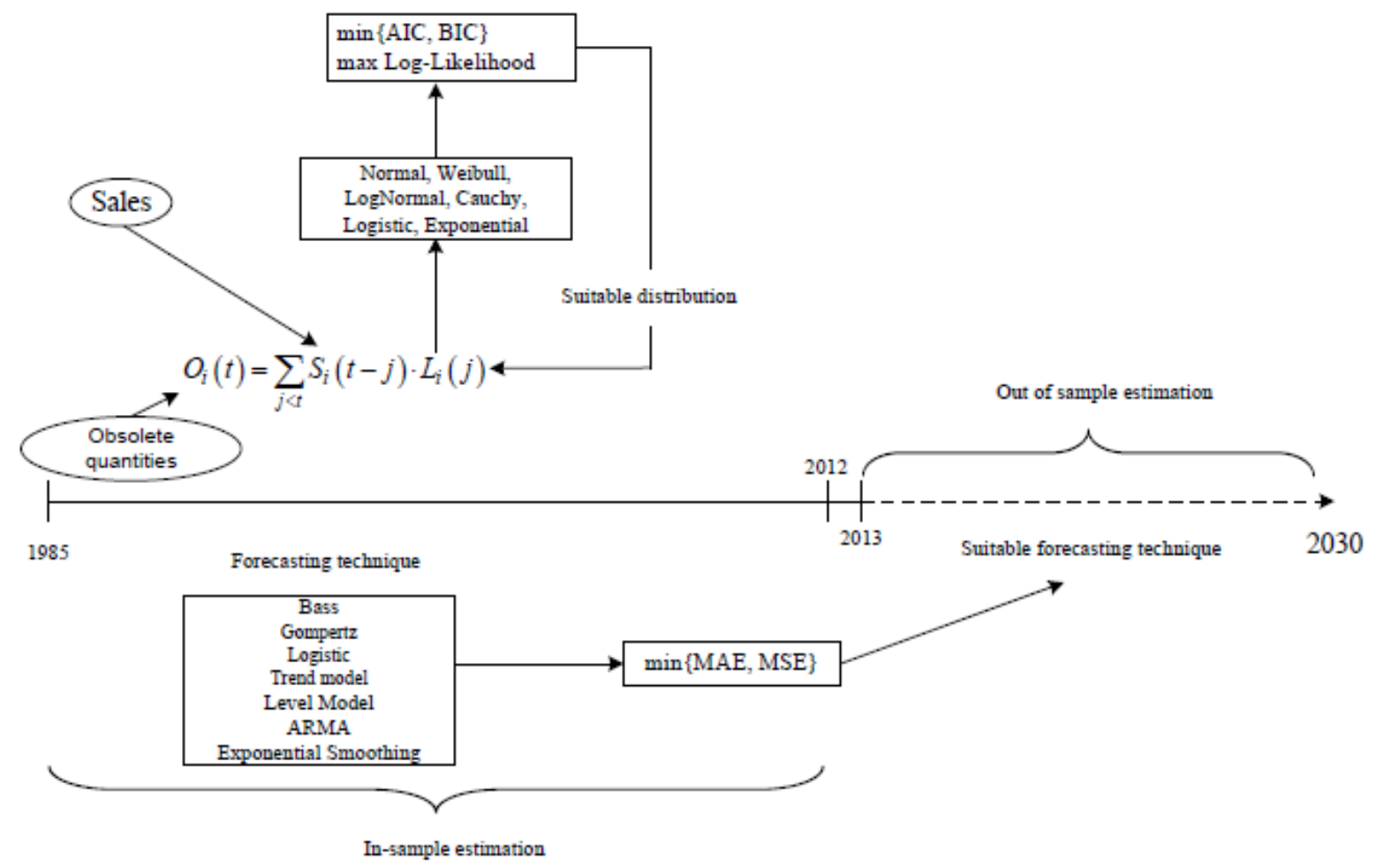

Figure 6: Graphical presentation of the proposed approach.

\section{Conclusion}

The acquisition of knowledge about the future amount of discarded ICT products (e.g. PCs) will significantly aid to construct establishments which will host, process, and eventually transform obsolete material into new recycled product. E-waste generation is growing rapidly over time due to the increased sales of ICT products (desktop computers, laptops, etc.). A critical factor for this rapid growth in e-waste generation is that technology nowadays is rapidly renewed. Thus, the lifespan, namely the life expectancy of a device or its use life until its owner decides to dispose of this device, is lower over the years. Of course, the lifespan does not decrease the same in all continents/countries due to different diffusion of the technology and various socio-economic factors. The lifespan 
distributions for each of the examined regions were estimated and with the use of cumulative computer sales, the expected quantities of obsolete computers were calculated.

An attempt to accurately forecast the obsolete amount of PCs, which will be out of use in leading economies of the world, is proposed. The in-sample methods which are applied demonstrate extremely precise amount of disposed products. A widely used model to predict time series, i.e. ARMA, exhibits accurate forecasts in 12 out of 25 cases, due to its flexibility to adjust to any kind of time series. On the other hand, other researches, which examine forecasting of e-waste generation, apply the Logistic model which in this dataset performs poor forecasts. The major drawback, from which non - linear trend models suffer, is the fact that they are very susceptible to initial conditions, while they are appropriate only for monotonically increasing data. Dynamic level models fit data very well but they do not perform in this dataset accurate forecasts for the amount of disposed computers. On the other hand, the trend model seems to generate more precise predictions compared to the naive model (Level model) and in some cases is proved to be the most appropriate. Last but not least, Exponential model is a very flexible forecast structure that lies between ARMA and Dynamic regression; it has proved to be very helpful in forecasting the amount of obsolete PCs for some countries of the dataset. Non - linear autoregressive models (e.g. Bass, Floyd) have been widely used in the field of marketing to successfully predict the rate of adopted ICT products. Bass model performs more accurate forecasts of obsolete computers than Floyd. This lies in the fact that Bass can easily encompass the dynamics of the diffusion (or disposal process) without the use of any explanatory variable other than past values of it. Overall, the forecasted quantities of obsolete computers are increasing in all the examined countries and the maximum percentage which will not be in use for the examined time horizon (2013 - 2030) may vary from $25 \%$ to $80 \%$, highlighting the need for efficient recycling and initiatives for re-use.

This paper presents a framework for accurate e-waste estimation. The continuous increase of e-waste quantities is one of the major problems of modern society. Providing an accurate estimation of future e-waste quantities is actually a very useful tool for policymakers and managers in order to design ewaste collection and treatment systems in an optimal way. Only when they are aware of the expected quantities, they will be able to build the required infrastructure and establish effective and efficient ewaste management systems. Also, based on information regarding e-waste quantities, manufacturers and retailers can redesign their operations in order to minimize the quantities that are discarded. To do this, they need the cooperation of relevant governmental bodies, but mostly the willingness and sensitivity to environmental issues of households and enterprises. The proposed methodology sets the foundations for new studies that would investigate both qualitative and quantitative factors that affect e-waste maximum rejection rates. 


\section{Acknowledgements}

Konstantinos Petridis would like to acknowledge that part of this work was co-funded within the framework of the Action «State Scholarships Foundation's (IKY) mobility grants programme for the short term training in recognized scientific/research centers abroad for candidate doctoral or postdoctoral researchers in Greek universities or research» from the European Social Fund (ESF) programme "Lifelong Learning Programme 2007 - 2013". 


\title{
Appendix - GAMS Code
}

Sets i countries /France,UK,Denmark,Italy,Germany,Finland,Norway,

Sweden,Greece,Estonia,Lithuania,Latvia,Australia,

NewZealand, Japan,Canada,USA,Mexico,Uruguay,Argentina,Brazil/

\author{
$\mathrm{p} 1$ paremeters /1, k/ \\ r Regions /r1*r5/ \\ *r1 Western Europe \\ *r2 Eastern Europe \\ *r3 North America \\ *r4 South/Middle America \\ *r5 Japan, Australia, New Zealand \\ *r6 Asia Pacific \\ t time period /1983*2012/; \\ Table par(r,p1) \\ $1 \quad \mathrm{k}$ \\ r1 $7.411853 \quad 4.75776$ \\ r2 $6.055942 \quad 5.231256$ \\ r3 $6.18003 \quad 4.754371$ \\ r4 $3.812666 \quad 4.259631$ \\ r5 $6.53819 \quad 5.784725$;
}

Parameter O(i,t) Obsolete Computer Quantities, L1(I,j) Weibull PDF, L2(j) Normal PDF;

$\operatorname{alias}(\mathrm{i}, \mathrm{ii})$;

alias(r,rr);

$\operatorname{alias}(\mathrm{t}, \mathrm{j})$;

$\operatorname{loop}(\mathrm{ii}$,

$\operatorname{loop}(\mathrm{rr}$,

if $((\mathrm{ORD}(\mathrm{ii})>=1$ AND ORD(ii) $<=8$ AND ORD(rr)=1),

L1(ii,j)=(par('r1','k')/par('r1','l'))**(ORD(j)-1)*(ORD(j)/par('r1','l'))*exp(-(ORD(j)/par('r1','l'))**par('r1','k')); 


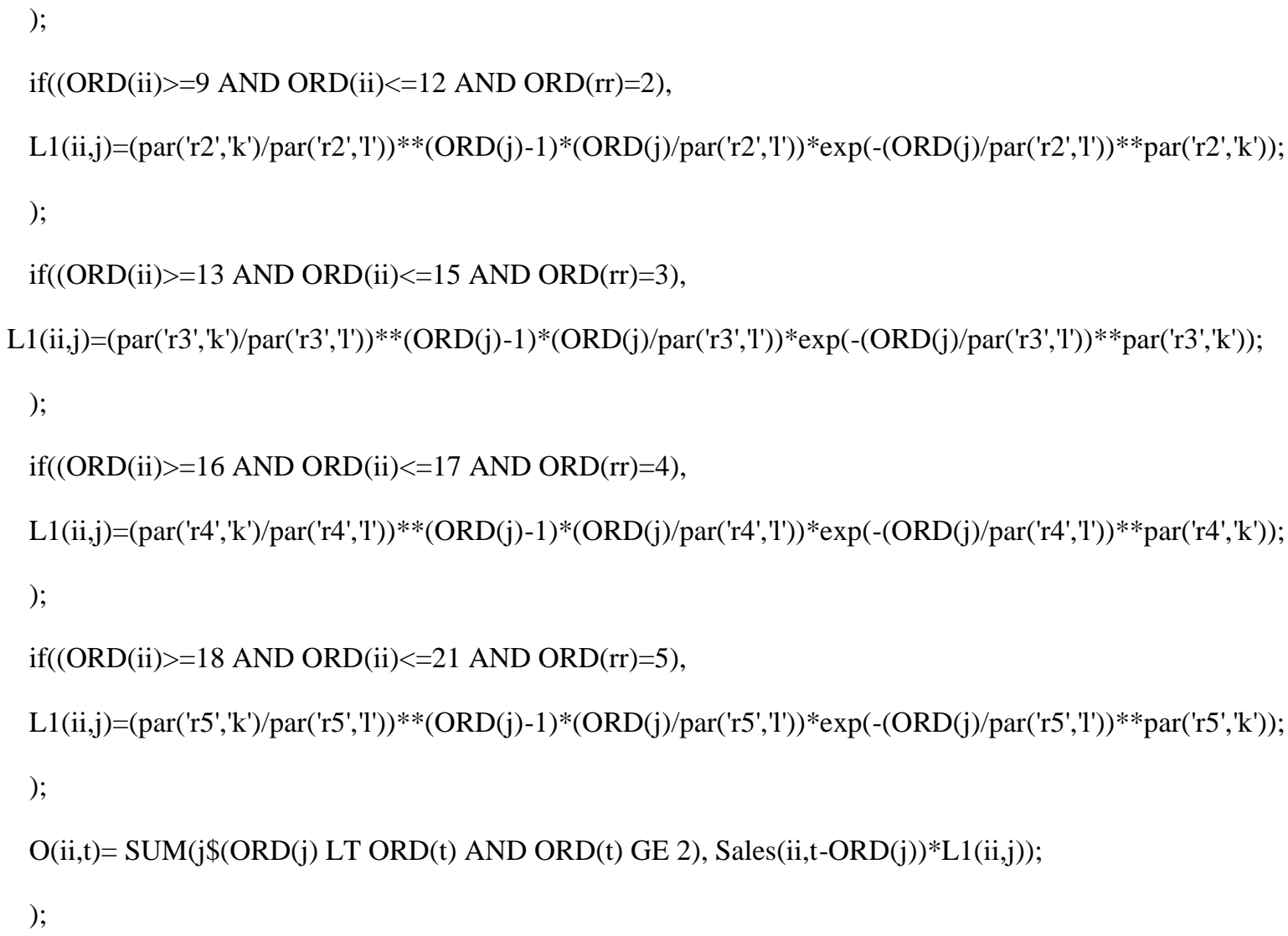




\section{References}

Afroz, R., Masud, M.M., Akhtar, R. and Duasa, J.B. (2013), Survey and analysis of public knowledge, awareness and willingness to pay in Kuala Lumpur, Malaysia - a case study on household WEEE management, Journal of Cleaner Production, Vol. 52, pp. 185-193.

Akaike, H. (1987), Factor analysis and AIC, Psychometrika, Vol. 52 No. 3, pp. 317-332.

Anderson, O.D. (1977), Time series analysis and forecasting: Another look at the Box-Jenkins approach, Journal of the Royal Statistical Society, Vol. 26 No. 4, pp. 285-303.

Araújo, M.G., Magrini, A., Mahler C.F. and Bilitewski, B. (2012), A model for estimation of potential generation of waste electrical and electronic equipment in Brazil, Waste Management, Vol. 32 No. 2, pp. 335-342.

Babbitt, C. W., Kahhat, R., Williams, E., \& Babbitt, G. A. (2009). Evolution of product lifespan and implications for environmental assessment and management: a case study of personal computers in higher education. Environmental science \& technology, 43(13), 5106-5112.

Bass, F.M. (1969), A new product growth for model consumer durables, Management Science, Vol. 15 No. 5 , pp. 215-227.

Bass, F.M., Krishnan, T.V. and Jain, D.C. (1994), Why the Bass model fits without decision variables, Marketing Science, Vol. 13 No. 3, pp. 203-223.

Chi, X., Wang, M.Y.L. and Reuter, M.A. (2014), E-waste collection channels and household recycling behaviors in Taizhou of China, Journal of Cleaner Production, Vol. 80, pp. 87-95.

Chung, S.S., Lau, K.Y. and Zhang, C. (2011), Generation of and control measures for, e-waste in Hong Kong, Waste Management, Vol. 31 No. 3, pp. 544-554.

Delignette-Muller, M.L., Dutang, C., Pouillot, R. and Denis J.-B. (2013), fitdistrplus: Help to fit of a parametric distribution to non-censored or censored data (Version 1.0-1), available at: http://cran.rproject.org/web/packages/fitdistrplus/index.html

Dwivedy, M. and Mittal, R.K. (2010), Estimation of future outflows of e-waste in India, Waste Management, Vol. 30 No. 3, pp. 483-491.

European Commission-RoHS Directive (2003), available at: http://ec.europa.eu/environment/waste/rohs_eee/legis_en.htm

European Commission-WEEE Directive (2003), available at:

http://ec.europa.eu/environment/waste/weee/legis_en.htm

Fisher, J.C. and Pry, R.H. (1971), A simple substitution model of technological change, Technological Forecasting and Social Change, Vol. 3, pp. 75-88.

Gößling-Reisemann, S., Knak, M. and Schulz, B. (2009), Product lifetimes and copper content of selected obsolete electric and electronic products, General Energy Research Department, University of Bremen, Germany, available at: http://ewasteguide.info/files/Goessling_2009_R09.pdf 
Hyndman, R.J. (2006), Another look at forecast-accuracy metrics for intermittent demand, FORESIGHT: The International Journal of Applied Forecasting, No. 4, pp. 43-46.

Hyndman, R.J., Koehler, A.B., Snyder, R.D. and Grose, S. (2002), A state space framework for automatic forecasting using exponential smoothing methods, International Journal of Forecasting, Vol. 18 No. 3, pp. 439-454.

Hyndman, R. J., and Khandakar, Y. (2007). Automatic time series for forecasting: the forecast package for R (No. 6/07). Monash University, Department of Econometrics and Business Statistics.

Jain, A. and Sareen, R. (2006), E-waste assessment methodology and validation in India, Journal of Material Cycles and Waste Management, Vol. 8, pp. 40-45.

Johansson, J. and Luttropp, C. (2009), Material hygiene: Improving recycling of WEEE demonstrated on dishwashers, Journal of Cleaner Production, Vol. 17 No. 1, pp. 26-35.

Kim, S., Oguchi, M., Yoshida, A. and Terazono, A. (2013), Estimating the amount of WEEE generated in South Korea by using the population balance model, Waste Management, Vol. 33 No. 2, pp. 474-483.

Kotabe, M. and Cunningham, P. (2002), Using Euromonitor database in international marketing research, Journal of the Academy of Marketing Science, Vol. 30 No. 2, pp. 172-175.

Kumar, P. and Shrihari, S. (2007), Estimation and material flow analysis of waste electrical and electronic equipment (WEEE) - A case study of Mangalore city, Karnataka, India, Proceedings of the International Conference on Sustainable Solid Waste Management, Chennai, India. pp. 148-154.

Leigh, N.G., Realff, M.J., Ai, N., French, S.P., Ross, C.L. and Bras, B. (2007), Modeling obsolete computer stock under regional data constraints: An Atlanta case study, Resources, Conservation and Recycling, Vol. 51, pp. 847-869.

Liu, X., Tanaka, M. and Matsui, Y. (2006), Generation amount prediction and material flow analysis of electronic waste: A case study in Beijing, China, Waste Management \& Research, Vol. 24, pp. 434445.

Lu, B., Liu, J., Yang, J. and Li, B. (2015), The environmental impact of technology innovation on WEEE management by Multi-Life Cycle Assessment, Journal of Cleaner Production, Vol. 89, pp. 148-158.

Makridakis, S., Wheelwright, S. C., \& Hyndman, R. J. (2008). Forecasting methods and applications. John Wiley \& Sons.

Matthews, H.S., McMichael, F.C., Hendrickson, C.T. and Hart, D.J. (1997), Disposition and end-of-life options for PCs, Green Design Initiative Technical Report \#97-10, Carnegie Mellon University, available at: http://www.ce.cmu.edu/ GreenDesign/comprec/NEWREPORT.PDF

McCarl, B. A. (2002). GAMS user guide: 2003.

Menikpura, S.N.M., Santo, A. and Hotta, Y. (2014), Assessing the climate co-benefits from Waste Electrical and Electronic Equipment (WEEE) recycling in Japan, Journal of Cleaner Production, Vol. 74, pp. 183-190.

Michalakelis, C., Varoutas, D. and Sphicopoulos, T. (2008), Diffusion models of mobile telephony in Greece, Telecommunications Policy, Vol. 32 No. 3-4, pp. 234-245. 
Murakami, S., Oguchi, M., Tasaki, T., Daigo, I. and Hashimoto, S. (2010), Lifespan of commodities, Part I: The creation of a database and its review, Journal of Industrial Ecology, Vol. 14 No. 4, pp. 598-612.

Nelen, D., Manshoven, S., Peeters, J.R., Vanegas, P., D’Haese, N. and Vrancken, K. (2014), A multidimensional indicator set to assess the benefits of WEEE material recycling, Journal of Cleaner Production, Vol. 83, pp. 305-316.

Nguyen, D.Q., Yamasue, E., Okumura, H. and Ishihara, K. (2009), Use and disposal of large home electronic appliances in Vietnam, Journal of Material Cycles and Waste Management, Vol. 11, pp. 358-366.

Oguchi, M., Kameya, T., Yagi, S. and Urano, K. (2008), Product flow analysis of various consumer durables in Japan, Resources, Conservation and Recycling, Vol. 52 No. 3, pp. 463-480.

Pant, D. (2013), E-waste projection using life-span and population statistics, International Journal of Life Cycle Assessment, Vol. 18 No. 8, pp. 1465-1469.

Polák, M. and Drápalová, L. (2012), Estimation of end of life mobile phones generation: The case study of the Czech Republic, Waste Management, Vol. 32 No. 8, pp. 1583-1591.

Qu, Y., Zhu, Q., Sarkis, J., Geng, Y. and Zhong, Y. (2013), A review of developing an e-wastes collection system in Dalian, China, Journal of Cleaner Production, Vol. 52, pp. 176-184.

Rahman, S. and Subramanian, N. (2012), Factors for implementing end-of-life computer recycling operations in reverse supply chains, International Journal of Production Economics, Vol. 140 No.1, pp. 239-248.

Robinson, B.H. (2009), E-waste: An assessment of global production and environmental impacts, Science of the Total Environment, Vol. 408, pp. 183-191.

Steubing, B., Böni, H., Schluep, M., Silva, U. and Ludwig, C. (2010), Assessing computer waste generation in Chile using material flow analysis, Waste Management, Vol. 30, pp. 473-482.

Streicher-Porte, M., Widmer, R., Jain, A., Bader, H.P., Scheidegger, R. and Kytzia, S. (2005), Key drivers of the e-waste recycling system: Assessing and modelling e-waste processing in the informal sector in Delhi, Environmental Impact Assessment Review, Vol. 25, pp. 472-491.

Schwarz, G. (1978), Estimating the dimension of a model, Annals of Statistics, Vol. 6 No. 2, pp. 461-464.

Wakolbinger, T., Toyasaki, F., Nowak, T. and Nagurney, A. (2014), When and for whom would e-waste be a treasure trove? Insights from a network equilibrium model of e-waste flows, International Journal of Production Economics, Vol. 154, pp. 263-273.

Walk, W. (2009), Forecasting quantities of disused household CRT appliances - A regional case study approach and its application to Baden-Württemberg, Waste Management, Vol. 29 No. 2, pp. 945-951.

Wang, F., Huisman, J., Stevels, A. and Baldé, C.P. (2013), Enhancing e-waste estimates: Improving data quality by multivariate Input-Output Analysis, Waste Management, Vol. 33 No. 11, pp. 2397-2407.

Yang, Y. and Williams, E. (2009), Logistic model-based forecast of sales and generation of obsolete computers in the U.S., Technological Forecasting and Social Change, Vol. 76 No. 8, pp. 1105-1114.

Yeh, C.-H. and Xu, Y. (2013), Sustainable planning of e-waste recycling activities using fuzzy multicriteria decision making, Journal of Cleaner Production, Vol. 52, pp. 194-204. 
Yoshida, A., Tasaki, T. and Terazono, A. (2009), Material flow analysis of used PCs in Japan, Waste Management, Vol. 29 No. 5, pp. 1602-1614.

Yu, J., Williams, E., Ju, M. and Yang, Y. (2010), Forecasting global generation of obsolete PCs, Environmental Science \& Technology, Vol. 44 No. 9, pp. 3232-3237.

Zeng, X., Song, Q., Li, J., Yuan, W., Duan, H. and Liu, L. (2015), Solving e-waste problem using an integrated mobile recycling plant, Journal of Cleaner Production, Vol. 90, pp. 55-59.

Zhang, L., Yuan, Z. and Bi, J. (2011), Predicting future quantities of obsolete household appliances in Nanjing by a stock-based model, Resources, Conservation and Recycling, Vol. 55 No. 11, pp. 1087-1094. 